\title{
No additive meta plasticity effects of accelerated iTBS with short inter-session intervals
}

Citation for published version (APA):

Thomson, A. C., de Graaf, T. A., Kenis, G., Rutten, B. P. F., Schuhmann, T., \& Sack, A. T. (2019). No additive meta plasticity effects of accelerated iTBS with short inter-session intervals. Brain stimulation, 12(5), 1301-1303. https://doi.org/10.1016/j.brs.2019.05.012

Document status and date:

Published: 01/01/2019

DOI:

10.1016/j.brs.2019.05.012

Document Version:

Publisher's PDF, also known as Version of record

Document license:

Taverne

Please check the document version of this publication:

- A submitted manuscript is the version of the article upon submission and before peer-review. There can be important differences between the submitted version and the official published version of record.

People interested in the research are advised to contact the author for the final version of the publication, or visit the DOI to the publisher's website.

- The final author version and the galley proof are versions of the publication after peer review.

- The final published version features the final layout of the paper including the volume, issue and page numbers.

Link to publication

\footnotetext{
General rights rights.

- You may freely distribute the URL identifying the publication in the public portal. please follow below link for the End User Agreement:

www.umlib.nl/taverne-license

Take down policy

If you believe that this document breaches copyright please contact us at:

repository@maastrichtuniversity.nl

providing details and we will investigate your claim.
}

Copyright and moral rights for the publications made accessible in the public portal are retained by the authors and/or other copyright owners and it is a condition of accessing publications that users recognise and abide by the legal requirements associated with these

- Users may download and print one copy of any publication from the public portal for the purpose of private study or research.

- You may not further distribute the material or use it for any profit-making activity or commercial gain

If the publication is distributed under the terms of Article $25 \mathrm{fa}$ of the Dutch Copyright Act, indicated by the "Taverne" license above, 


\section{No additive meta plasticity effects of accelerated iTBS with short inter- session intervals}

\section{To the Editor,}

Many studies have aimed to optimize repetitive transcranial magnetic (rTMS) protocols, focusing on shortening protocol length, increasing plasticity effect size, and decreasing variability. The Theta Burst protocols (TBS) for example require only minutes of application duration and reportedly induce less variable and longer lasting plasticity effects compared to classic rTMS protocols [1]. Intermittent TBS (iTBS) is a 3-min protocol, which has been shown to increase cortical excitability for up to 1 -h post stimulation [1]. However, several studies have reported difficulty in replicating these established iTBS effects [2-6]. It is important that such findings are reported to combat positive publication bias, especially since iTBS is increasingly used in both research and clinical environments. If iTBS effects on excitability, possibly extended to clinical treatment efficacy, are not very reliable, then research on protocol optimization must continue.

Given its short duration, iTBS has also been administered repeatedly within one visit/day ('accelerated iTBS'), which might stabilize and/or amplify neuroplastic effects. Accelerated iTBS protocols were recently applied in depression treatment with positive results $[7,8]$. Hypothetically, accelerated iTBS could not only shorten the treatment process, but also lead to enhanced and more stable (reliable) effects on cortical excitability. Initial iTBS sessions could prime, normalize, or amplify the neuroplastic effects of subsequent sessions [9]. However, the efficacy of accelerated iTBS has never been empirically demonstrated through objective, neurophysiological measures in healthy volunteers.

In the study detailed in the Supplementary Material, we investigated the effects of standard iTBS (single-iTBS session) and accelerated iTBS (five repeated iTBS sessions) on motor cortical excitability, assessed with motor-evoked potentials (MEPs) in 20 healthy participants. We included two short inter-iTBS intervals, 15 minutes and 8 minutes, evaluating effects on magnitude and variability of MEPs. In this fully within-subject design, effects of standard and accelerated iTBS were compared to placebo (sham) iTBS. We analyzed whether accelerated iTBS had stronger, more consistent aftereffects when compared to standard iTBS, if 8 minutes versus 15 minutes between iTBS protocols had different results, and if these effects were longer lasting. MEPs were measured every 10 minutes for up to 90 minutes following each procedure.

TMS was applied through a MagVenture figure of 8 TMS coil and X100 stimulator, using neuronavigation to mark the individual motor hotspot. Each iTBS session consisted of the Huang et al. (2005) published protocol, at an intensity of $80 \%$ Active Motor Threshold (AMT). To elicit MEP's; single pulses were given at 120\% Resting
Motor Threshold (RMT) in blocks of 30 pulses per time point. All participants completed all 4 experimental sessions, none reported negative side effects.

Overall we found no significant effect of accelerated iTBS or standard iTBS motor cortex stimulation on MEP amplitude, both when baseline-normalized and when subtracted from placebo responses (detailed results are described in Supplementary Material). In post-hoc analysis, we wanted to better understand the pattern of responses. These analyses were therapeutically motivated; an opposite response to iTBS, i.e. a decrease instead of an increase of excitability, could be harmful to patients, and therefore if accelerated iTBS has fewer opposite responders this would be clinically relevant. In our iTBS protocol, $40 \%$ of participants responded with a decrease in MEP amplitude, i.e. the 'opposite' response, while only $20 \%$ showed this opposite response after accelerated iTBS (with either 15 or 8 minute intervals between iTBS sessions), though these differences in distributions were not statistically significant. Details and further post-hoc analysis are described in Supplementary material. Experimental design, response distributions, MEP responses over time, and placebo-subtracted MEP responses over time are shown in Fig. 1.

In line with several previous reports, we did not find increased MEP amplitudes after standard iTBS relative to placebo iTBS [2-6]. Importantly, we found that accelerated iTBS did not amplify/stabilize neuroplastic effects, since neither the accelerated 8 nor 15 -min interval protocols had significant effects on MEPs. There are several reasons for why we found no effect of both single and accelerated iTBS on motor cortex excitability.

First, we hypothesized that accelerated iTBS exerts its effects through different plasticity mechanisms than a single session of iTBS, which would be represented through MEP amplitude. However, MEPs are notoriously variable, with reportedly large inter-and intra subject variability following iTBS protocols [5]. Additionally, we assessed excitability changes immediately and up to 90 minutes after stimulation. In the clinic, where accelerated iTBS proved promising [7,8], effects are assessed weeks after treatment. It is possible that the additive plasticity effects of accelerated iTBS cannot be revealed by MEP measurements immediately following stimulation.

Another reason why we see no additive plasticity effects of accelerated iTBS might be the short intervals between repeated iTBS protocols. Animal studies in rat hippocampal slices have shown that a delay of 1 hour between iTBS sessions was necessary for additive LTP effects to occur [10]. Specifically, the longer interprotocol intervals were required for recruitment of synapses that were not affected by the first iTBS stimulation. The first iTBS session 
A.

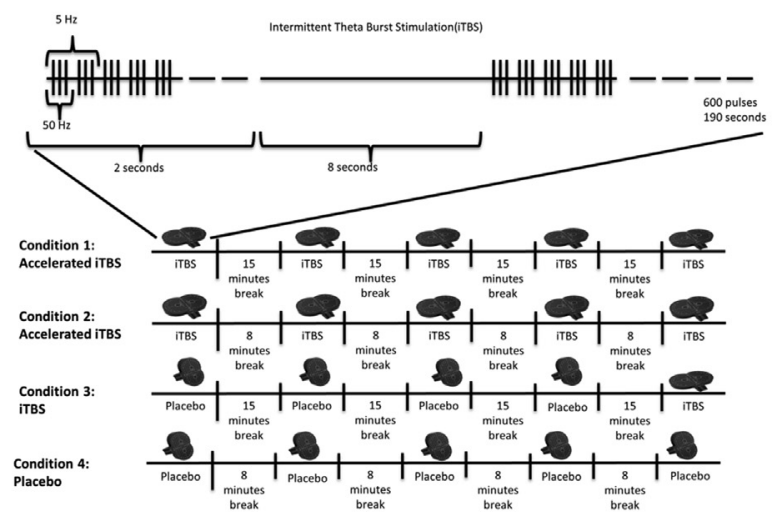

C.

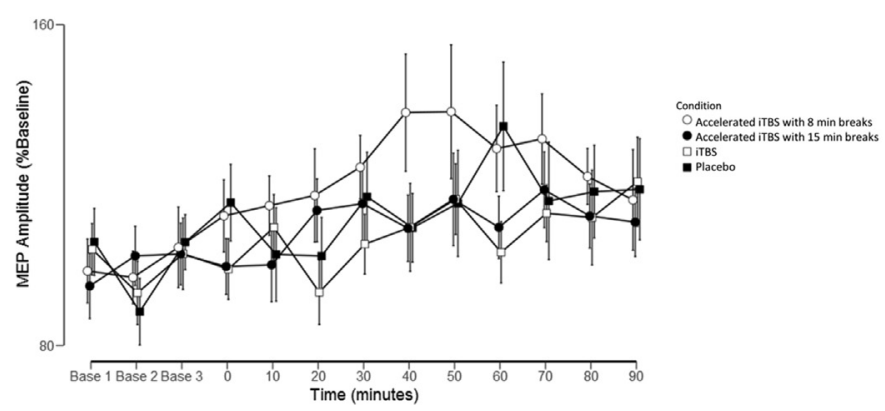

B.

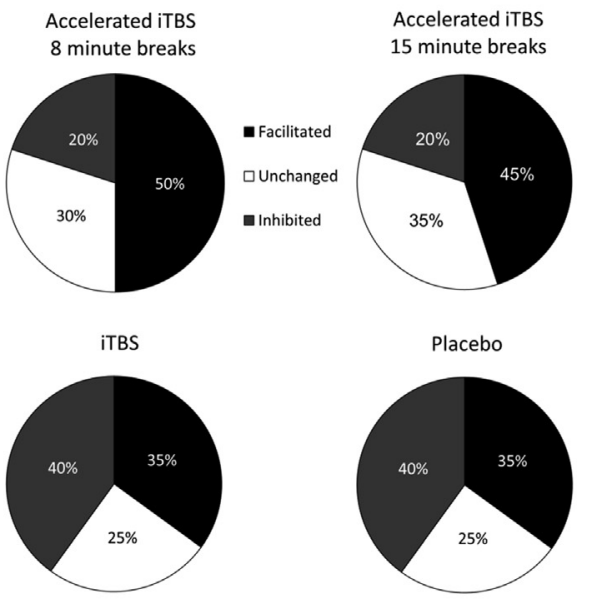

D.

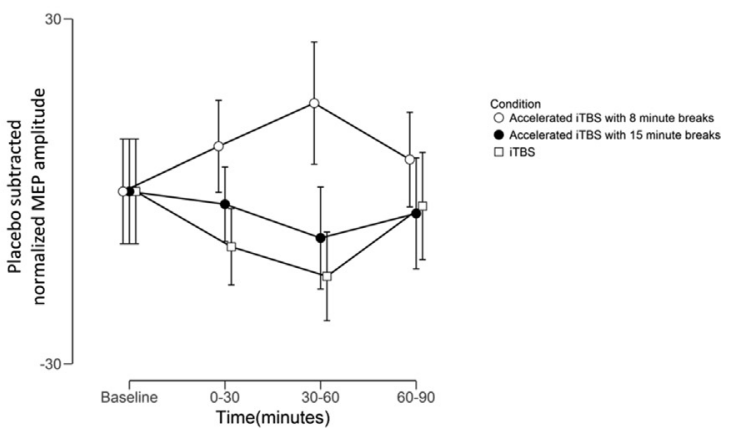

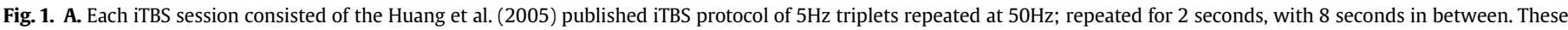

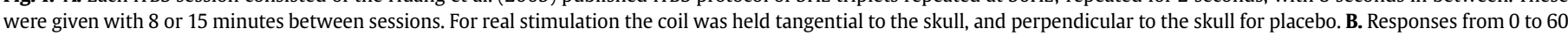

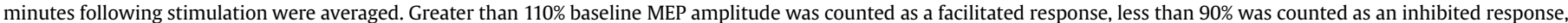

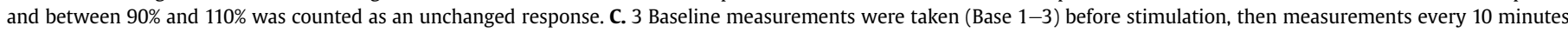

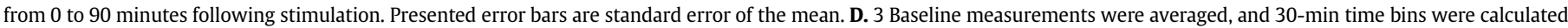
for the post-rTMS measurements. Presented error bars are standard error of the mean.

is thought to induce LTP in low-threshold synapses, and to lower the threshold for higher-threshold synapses. However, short breaks of 10-30 minutes are not long enough for these high-threshold synapses to be lowered [10]. There is evidence that $40-50$ minutes is required for the initiation and protein synthesis of the synaptic machinery necessary for refractory LTP effects in synapses with different plasticity thresholds [10].

It is important to publish these negative findings to combat publication bias and to promote future studies considering the variability and patterns of response in brain stimulation protocols. Furthermore, accelerated iTBS has already been explored in treatment, making it especially relevant to communicate failures to reproduce hypothesized effects on basic neurophysiological mechanisms. Combining our negative findings with previous animal studies, we conclude that it may take multiple iTBS sessions and/ or longer intervals (45-60 minutes) between sessions for synapses to undergo the necessary plasticity mechanisms [10].

\section{Conflict/declaration of interest}

None.

\section{Acknowledgements}

Funding Source: This work was supported by the Netherlands Organisation for Scientific Research (NWO, Veni to TDG 451-13-
024; Vici to AS 453-15-008), and an internal grant from the Centre for Integrative Neuroscience at Maastricht University.

\section{Appendix A. Supplementary data}

Supplementary data to this article can be found online at https://doi.org/10.1016/j.brs.2019.05.012.

\section{References}

[1] Huang Y-Z, Edwards MJ, Rounis E, Bhatia KP, Rothwell JC. Theta burst stimulation of the human motor cortex. Neuron 2005;45(2):201-6 [published Online First: Epub Date]|, https://doi.org/10.1016/j.neuron.2004.12.033.

[2] Lopez-Alonso V, Cheeran B, Rio-Rodriguez D, Fernandez-Del-Olmo M. Interindividual variability in response to non-invasive brain stimulation paradigms. Brain Stimul 2014;7(3):372-80. https://doi.org/10.1016/j.brs.2014. 02.004 [published Online First: Epub Date]|.

[3] Wassermann EM. Variation in the response to transcranial magnetic brain stimulation in the general population. Clin Neurophysiol: Off J Int Feder Clin Neurophysiol 2002;113(7):1165-71.

[4] Jung NH, Delvendahl I, Kuhnke NG, Hauschke D, Stolle S, Mall V. Navigated transcranial magnetic stimulation does not decrease the variability of motor-evoked potentials. Brain Stimul 2010;3(2):87-94. https://doi.org/ 10.1016/j.brs.2009.10.003 [published Online First: Epub Date]|.

[5] Schilberg L, Schuhmann T, Sack AT. Interindividual variability and intraindividual reliability of intermittent theta burst stimulation-induced neuroplasticity mechanisms in the healthy brain. J Cogn Neurosci 2017;29:1530-8898. https://doi.org/10.1162/jocn_a_01100 (Electronic)).

[6] Tse NY, Goldsworthy MR, Ridding MC, et al. The effect of stimulation interval on plasticity following repeated blocks of intermittent theta burst stimulation. 
Sci Rep-Uk 2018;8(1):8526. https://doi.org/10.1038/s41598-018-26791-w [published Online First: Epub Date]|.

[7] Desmyter S, Duprat R, Baeken C, Van Autreve S, Audenaert K, van Heeringen K. Accelerated intermittent theta burst stimulation for suicide risk in therapyresistant depressed patients: a randomized, sham-controlled trial. Front Hum Neurosci 2016;10:480. https://doi.org/10.3389/fnhum.2016.00480 [published Online First: Epub Date]|.

[8] Desmyter S, Duprat R, Baeken C, Bijttebier S, van Heeringen K. The acute effects of accelerated repetitive Transcranial Magnetic Stimulation on suicide risk in unipolar depression: preliminary results. Psychiatr Danub 2014;26(Suppl 1):48-52.

[9] Muller-Dahlhaus F, Ziemann U. Metaplasticity in human cortex. Neuroscientist: Rev J Bringing Neurobiol Neurol Psychiatr 2015;21(2):185-202. https:/ doi.org/10.1177/1073858414526645 [published Online First: Epub Date]|.

[10] Kramar EA, Babayan AH, Gavin CF, et al. Synaptic evidence for the efficacy of spaced learning. Proc Natl Acad Sci U S A 2012;109(13):5121-6. https:/ doi.org/10.1073/pnas.1120700109 [published Online First: Epub Date]|.

\section{Alix C. Thomson}

Department of Cognitive Neuroscience, Faculty of Psychology and Neuroscience, Maastricht University, Maastricht, the Netherlands

Centre for Integrative Neuroscience, Maastricht University, Maastricht, the Netherlands

Maastricht Brain Imaging Centre (MBIC), Maastricht University, Maastricht, the Netherlands

School for Mental Health and Neuroscience (MHeNS), Department of Psychiatry and Neuropsychology, Faculty of Health, Medicine and Life Sciences, Maastricht University, Maastricht, the Netherlands

Tom A. de Graaf Department of Cognitive Neuroscience, Faculty of Psychology and Neuroscience, Maastricht University, Maastricht, the Netherlands

Centre for Integrative Neuroscience, Maastricht University, Maastricht, the Netherlands

Maastricht Brain Imaging Centre (MBIC), Maastricht University, Maastricht, the Netherlands

Gunter Kenis Centre for Integrative Neuroscience, Maastricht University, Maastricht, the Netherlands
School for Mental Health and Neuroscience (MHeNS), Department of Psychiatry and Neuropsychology, Faculty of Health, Medicine and Life Sciences, Maastricht University, Maastricht, the Netherlands

Bart P.F. Rutten

Centre for Integrative Neuroscience, Maastricht University, Maastricht, the Netherlands

School for Mental Health and Neuroscience (MHeNS), Department of Psychiatry and Neuropsychology, Faculty of Health, Medicine and Life Sciences, Maastricht University, Maastricht, the Netherlands

Teresa Schuhmann ${ }^{1}$

Department of Cognitive Neuroscience, Faculty of Psychology and Neuroscience, Maastricht University, Maastricht, the Netherlands

Centre for Integrative Neuroscience, Maastricht University, Maastricht, the Netherlands

Maastricht Brain Imaging Centre (MBIC), Maastricht University, Maastricht, the Netherlands

Alexander T. Sack ${ }^{1}$

Department of Cognitive Neuroscience, Faculty of Psychology and Neuroscience, Maastricht University, Maastricht, the Netherlands

Centre for Integrative Neuroscience, Maastricht University, Maastricht, the Netherlands

Maastricht Brain Imaging Centre (MBIC), Maastricht University, Maastricht, the Netherlands

* Corresponding author. Oxfordlaan 55, 6229 EV, Maastricht, the Netherlands. E-mail address: alix.thomson@maastrichtuniversity.nl (A.C. Thomson).

9 May 2019 Available online 17 May 2019

\footnotetext{
1 Equal contribution.
} 